\title{
Why art matters for youth mental health: A youth led participatory insight analysis
}

When has art not changed the world?

Engagement with the arts takes on a higher significance during unsettled times, helping with mental strain and unleashing the imagination to escape, innovate and create new ways of being ${ }^{1}$

Kamala Easwaran ${ }^{1 *}$, Lakshmi Narasimhan ${ }^{1 *}$, Anussha Murali ${ }^{1}$, Deepika Easwaran ${ }^{1}$, Tasneem Raja², and Yog Varun Japee ${ }^{1}$,

*joint first authors

1 Sumunum Arts and Wellbeing Pvt. Ltd

2 Udaan - Tata Trusts

Corresponding author

Kamala Easwaran

Sumunum Arts and Wellbeing Pvt. Ltd.

271, E V R Periyar High Road

Ankur Manor 1st Floor

Chennai 600 010, India

kamala@sumunum.com

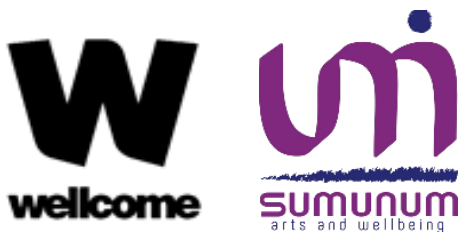

UNATAN

${ }^{1}$ Ken Arnold \& Danielle Olsen (Wellcome Trust), Art Therapy: This is how the arts can sharpen mental health research; World Economic Forum. 


\section{Abstract}

Background: Evidence indicates that arts involvement can result in significant improvements in communication and social skills, and relationships among mental health service users. While some evidence of the efficacy and effectiveness of arts-based interventions exist, detailed synthesis and analysis of the modalities of their functioning amongst young people do not.

Objective: This participatory insight analysis aims to synthesise available evidence on the effects of arts engagement for youth with depression \& anxiety. It co-produces knowledge with lived experience experts through multi-modal arts workshops that culminate in the creation of an artistic showcase of individual and collective experiences of navigating the ill-health wellness trajectory.

Methods: A scoping review was conducted to synthesise available evidence. A range of databases and systematic hand searches were conducted by three reviewers who independently screened the articles for inclusion and extracted relevant data. The arts engagement sessions were conceptualised by a seasoned arts educator, resulting in an intervention operationalised in thirty sessions over two months.

Results: Thirty-six studies were included in the review. Eighteen individuals enrolled in the arts engagement sessions. Preliminary evidence indicates that participation in arts interventions has positive mental health gains for young people.

Conclusion: Engagement with arts results in predominantly positive outcomes for youth with depression and anxiety. We identified a typology of essential ingredients of effective arts interventions, however, cannot point to individual effectiveness of each ingredient. Arts engagement has significant potential as a mental health prevention, promotion, and advocacy tool for young people with depression and anxiety. 


\section{Background}

Mental health problems are leading causes of health-related burden for young people under 24 (Gore et al., 2011, Patel et al., 2007, Mokdad et al., 2016). Adolescence and youth are formative periods of particular importance to onset of mental health conditions. Three quarters of mental health conditions are estimated to begin by the mid-20s. Over a quarter of the disability-adjusted life years (DALYs) contributed by mental health conditions are from youth under the age of 19 (Sassi, 2006). Despite unequivocal evidence of mental health challenges presenting themselves between the ages of 14 to 24 , data indicate that mental health needs among adolescents and young people are largely unmet, resulting in enduring liabilities of discrimination, heightened risk of suicide (Vijayakumar et al., 2005), educational disruptions and altered life prospects. The gap between need and appropriate services is of particular public health significance in the global south - a term encompassing emerging economies typically with a history of being colonised, which are characterised by large youth populations(Lund et al., 2011).

Since the 1970s, global efforts to address the 'treatment gap' have focused on integration of psychiatric services into public health systems at the primary level (Lund et al., 2016, Patel et al., 2009). However, this strategy has not produced desired results for meeting youth mental health needs, particularly in countries of the Global South which are low resource settings with exceptionally burdened public health systems (Gulliver et al., 2010, Collins et al., 2011, Patel, 2007). Further, some scholars have questioned the appropriateness of mental health treatment epistemologies derived from majoritarian samples in the Western contexts to address needs of people located in diverse socio-cultural and political contexts.

Developments in mental health science have provided an impetus in research to explore arts interventions as tools to promote, prevent, manage, or facilitate recovery across the life-course (Heenan, 2006, Hacking et al., 2006). For people experiencing depression and anxiety, there is promising preliminary evidence highlighting the impact of art in addressing social withdrawal, fearfulness, anxiety and sadness accompanying these conditions by encouraging social participation and allowing them to give voice to their experiences, which particularly in group settings helped to address the sense of isolation (Fancourt and Finn, 2019, Coulter and Gordon-Nesbitt, 2016).

However, the academic literature available linking arts with mental health is limited to the fields of health sciences and psychology and lacks perspectives of art practitioners and youth with lived experience (Staricoff, 2004, Fancourt, 2017). On the other hand, while there exist artist 
groups (dance troupes, theatre groups, music companies and so on) and non-profit organisations working at the intersection of arts, health and education, there is a lack of documentation of practice, processes and associated impact (Secker et al., 2009). Existing grey literature paints a vibrant picture of the possibilities attached to engaging in arts not only for addressing depression and anxiety in youth but also in improving mental health literacy and exploring mental health in relation to socio-cultural issues (Spandler et al., 2007). To give one example, Pandies Theatre Company's 1997 production 'She's MAD!' explored the incarceration of women under the 1987 Mental Health Act (Crossley et al., 2019, Kumar, 2004, Greig, 2008). Performed in Delhi's slum settlements, it examined the embeddedness of patriarchal values and carceral features within the care system (Kumar, 2004).

For arts engagement to become tenable, more readily available form of cost-effective access to mental health care for youth, exploring the efficacy and appropriateness of such alternatives to conventional psychotropic medication or psychotherapy becomes relevant. Thus, there is a critical need to integrate findings from existing literature on arts and mental health, and to dialogue with youth lived experience experts collaboratively with mental health and arts practitioners on arts interventions.

\section{Study Approach}

This participatory insight analysis combined an integrative review (Whittemore and Knafl, 2005) with feedback from young people with lived experiences of depression and anxiety. This feedback was elicited through participation in tri-weekly multi-modal arts workshops (Kagan et al., 2005, Tarr et al., 2018) aimed at gaining insight into individual and collective experiences of depression and anxiety, and their views on arts engagement to achieve mental health gains.

The two components of the participatory insight analysis:

1. Scoping Review: A comprehensive search of existing literature on theatre and arts-based involvement aimed at influencing mental health outcomes among youth with experiences of depression and/or anxiety.

2. Multimodal Arts Engagement with Youth with Lived Experience: Arts engagement sessions aimed at eliciting individual experiences and perspectives on living with anxiety and depression. The process of evolving an interactive art showcase involved a knowledge co-production process through which their perspectives on arts engagement as a mental health prevention and treatment modality 


\section{The main questions that the study sought to answer are:}

1. What does the available evidence tell us about theatre and arts-based interventions aimed at influencing mental health of 14-24-year olds experiencing depression and anxiety?

2. What are youth perspectives on the role of arts-based interventions in mental health?

\section{Arts intervention \& engagement}

The Sumunum arts intervention used multimodal arts workshops to engage participants between the ages of 14-24. The arts engagement sessions were underpinned by a recovery approach that focused on rebuilding hope, identity, meaning and responsibility. Sessions were designed to create a safe space for young people to discover their own vocabularies to articulate and express mental health needs.

\section{Results}

A total of 5746 records were identified on electronic databases, of which 471 records were excluded for not meeting the inclusion criteria through title and abstract screening and 5200 records were identified as duplicates (See PRISMA diagram Fig. 1). An additional 67 records were identified through hand search.

Reasons for exclusion at the stage of title and abstract level were as follows: population criteria not met, conference presentation, book chapter or poster, program description with no evaluation, descriptive reviews, study in non-English language, and year of publication criteria not met. From these, 75 studies were examined as full-text articles, out of which 16 were from the Global South context. 


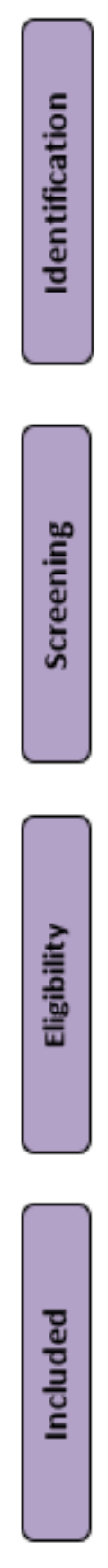

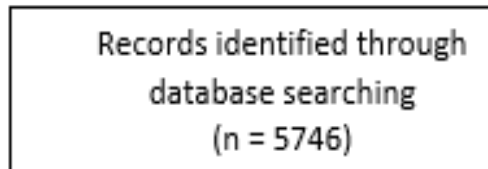

$(n=5746)$
Additional records identified through other sources

$(n=67)$
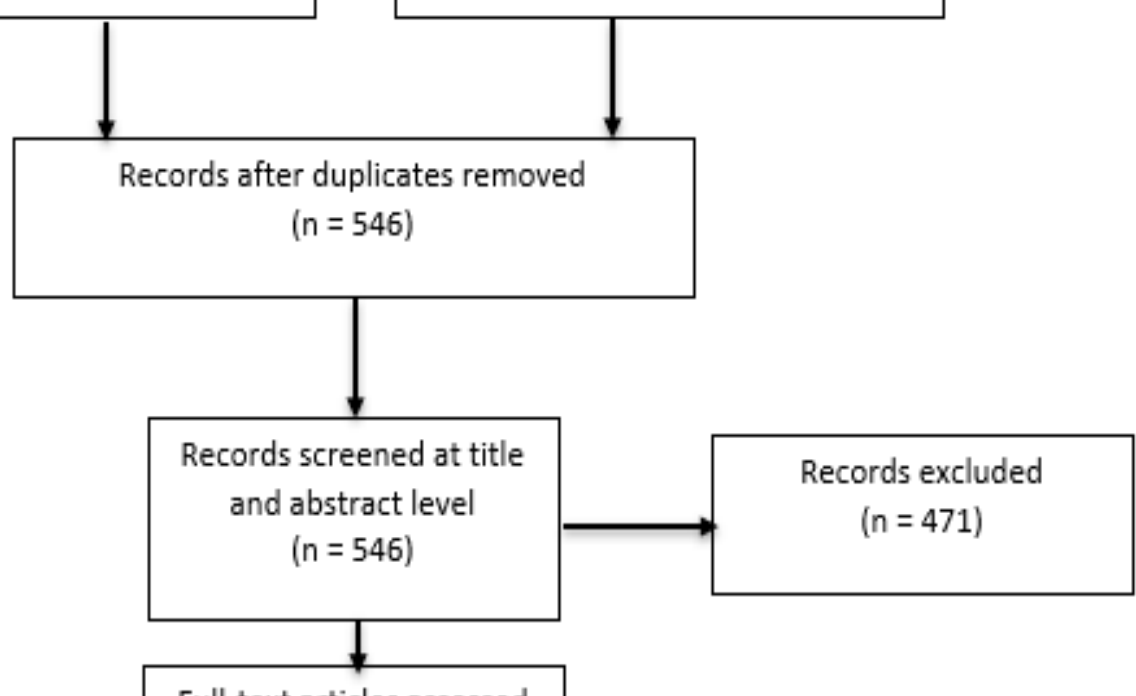

Full-text articles assessed for eligibility ( $n=75)$

Full-text articles excluded, with reasons

$$
\text { ( } n=39 \text { ) }
$$

Does not meet age criteria: $n=24$

Does not meet intervention and outcomes criteria: $n=9$ Not an intervention: $n=2$ Unable to retrieve full text: $n=3$ Does not meet population

Studies included in qualitative synthesis $(n=36)$

Figure 1: PRISMA Flow Diagram (Moher et al., 2009)

The studies $(n=36)$ included for final analysis included 27 studies from the Global North and 9 studies from the Global South.

\section{Characteristics}

Table 1 describes characteristics of studies included in this scoping review. While 25 studies recruited participants without formal diagnosis of depression or anxiety, 1 study worked with individuals diagnosed with depression and/or anxiety, 4 studies worked with samples drawn 
using screening tools to identify individuals meeting mild to severe ratings on self-report depression and anxiety inventories, and 6 studies engaged with populations diagnosed with mental health conditions including but not limited to depression and anxiety.

\section{Table 1: Characteristics of included studies ( $n=36)$}

Population

Adolescents
Young Adults

Both

\section{Study design}

$\mathrm{RCT}$

$\mathrm{nRCT}$

Single group pre-post

Qualitative

Mixed methods

\section{Setting}

School

University

Community

Child Care Institutions

(within criminal justice

systems)

In- and Out-patient

Facilities

Others / Not Specified

Arts Modalities**

\begin{tabular}{|r|r|}
\hline Visual Art & $7(2 ; 5)$ \\
\hline Theatre & 1 \\
Music & $7(2 ; 5)$ \\
\hline Psychodrama & 0 \\
\hline Dance/Movement & $3(1 ; 2)$ \\
\hline Multi-modal & $7(5 ; 2)$ \\
\hline
\end{tabular}

Others / Not Specified

6

7

$2^{*}$

5

1

\section{Global South}

Total

22
4
1

5

4

0

7

5

\begin{tabular}{c|c|}
\hline 6 & 1 \\
\hline 5 & 2 \\
\hline 7 & 2 \\
\hline $2^{*}$ & 0 \\
\hline
\end{tabular}

11

$1 \quad 7$

$2 \quad 7$

$2 \quad 9$

0

$11 \quad 12$

$3 \quad 3 \quad 6$

$\begin{array}{lll}6 & 1 & 7\end{array}$

123

0

5

2

*Note: Studies employed a mixed methods nRCT design $(n=1)$ and mixed methods single-group pre-post design $(n=1)$

${ }^{* *}$ Note: Includes arts participation interventions and creative arts therapies. Where applicable, $\mathrm{N}=\mathrm{x}(\mathrm{y} . \mathrm{z})$ where $x$ refers to total number of interventions using the art modality, $y$ refers to number of interventions involving arts participation and $z$ refers to interventions using creative art therapies situated within the specific modality.

\section{Intervention Ingredients}

Few studies included in this review contain reasonably detailed descriptions of interventions.

These were heterogeneous in art form, sampled populations, design and setting. The analysis 
of these diverse interventions converge to indicate eight ingredients that may be employed by arts-based interventions for youth depression and anxiety (Table 2).

\section{Table 2: Arts-based Interventions: Ingredients for Youth with Depression and Anxiety}

\begin{tabular}{|l|l|}
\hline $\begin{array}{l}\text { Ingredient } \\
\text { Multi-expressive }\end{array}$ & $\begin{array}{l}\text { Description } \\
\text { Self-expression in diverse } \\
\text { ways }\end{array}$ \\
\hline Safe Spaces & $\begin{array}{l}\text { Opportunity to feel heard, } \\
\text { hear experiences that } \\
\text { resonate and to feel like } \\
\text { they belong without any } \\
\text { judgement }\end{array}$ \\
\hline
\end{tabular}

$\begin{array}{ll}\text { 'Self-Reflective } & \text { Creation of personal } \\ \text { Meaning Making } & \begin{array}{l}\text { schemas - reflection of their } \\ \text { experiences to develop } \\ \text { personal vocabularies }\end{array}\end{array}$

Improvisational Spontaneous creation \& enhancing imagination

\section{Dynamic}

Responsive to participant

\section{Example}

SmithBattle et al (2017) evaluated Moms growing together (MGT) an action-based, multi sensorial 10 session intervention delivered over 12 weeks that included "movement, dramatic enactment, art, music, storytelling, and ritual" (SmithBattle et al., 2017).

Cortina et al (2015) evaluated The Art Room, a structured bi-weekly arts engagement in school settings for a minimum of 10 weeks where children (typically identified by teachers for difficulties) are offered the opportunity to express themselves and listen to others in a "calm environment within the school but away from the classroom and additional school pressures" (Cortina and Fazel, 2015).

Mueller et al (2010) evaluated "Make a Difference" MAD About Art, an intervention that involved children from deprived communities making 'hero' books about their own life journey focussed on self-concept, selfadvocacy, and empowerment (Mueller et al., 2011).

Hamamci (2006) conducted a study to compare the effects of psychodrama integrated with CBT, and with group CBT in the treatment of moderate depression. Psychodramatic role playing provides a platform to generate new ways of thinking. The spontaneity helps produce alternative thoughts, and thereby supporting individuals in disrupting the cycle of negative mood, ruminating thoughts, and dysfunctional behaviours (Hamamci, 2006). needs
Porter et al (2017) evaluated a music therapy (MT) intervention of 12 weekly sessions each of 30 minutes with each session led by the participants who were invited to choose an instrument and play as they wished to express themselves, including making their own personalised CDs. The therapist tailored supports 


\begin{tabular}{|c|c|c|}
\hline & & $\begin{array}{l}\text { for free expression based on individual needs (Porter } \\
\text { et al., 2017). }\end{array}$ \\
\hline Participatory & $\begin{array}{l}\text { Shaped by participant } \\
\text { voices and actions }\end{array}$ & $\begin{array}{l}\text { Kim et al (2014) studied the effects of group art therapy } \\
\text { and mindfulness based breathwork on subjective well- } \\
\text { being of depressed and anxious adolescents. The art } \\
\text { activities allow for a natural expression of the } \\
\text { subconscious and helps reveal painful thoughts and } \\
\text { emotions without verbal engagement. Participants } \\
\text { were free to lead the group sessions in the direction of } \\
\text { their comfort. Being allowed to engage and drive the } \\
\text { session at their own pace led to strong bonding, } \\
\text { sharing of feelings and processing of difficult emotions } \\
\text { (Kim et al., 2014). }\end{array}$ \\
\hline $\begin{array}{l}\text { Public } \\
\text { Performance }\end{array}$ & $\begin{array}{l}\text { Live art creating dialogue } \\
\text { with larger audience }\end{array}$ & $\begin{array}{l}\text { Keller et al (2017) evaluated Let's Talk, an intervention } \\
\text { that facilitated theatre workshops where students met } \\
\text { as a group bi-weekly for } 12 \text { weeks "to share their } \\
\text { personal experiences with suicide and depression and } \\
\text { to collaboratively write a unique play based on their } \\
\text { experiences". Performances for peers and audience } \\
\text { members followed by discussions moderated by a } \\
\text { mental health professional formed a part of the } \\
\text { intervention, opening the space for interactive learning } \\
\text { around themes of suicide, loss and prevention (Keller } \\
\text { et al., 2017). }\end{array}$ \\
\hline Activism & $\begin{array}{l}\text { Art as a means to effect } \\
\text { social change }\end{array}$ & $\begin{array}{l}\text { Fanian et al (2015) evaluated Ko" "ts'il htła ("We Light } \\
\text { the Fire"), a 5-day intervention for indigenous youth "to } \\
\text { explore critical issues facing their community and their } \\
\text { lives and to find solutions together using the arts." } \\
\text { (Fanian et al., 2015) }\end{array}$ \\
\hline $\begin{array}{l}\text { Peer } \\
\text { Engagement }\end{array}$ & $\begin{array}{l}\text { Role of art interventions in } \\
\text { positively impacting peer } \\
\text { relations }\end{array}$ & $\begin{array}{l}\text { Momartin et al (2018) STARTTS "Project Bantu } \\
\text { Capoeira Angola" offered a non-competitive, non- } \\
\text { judgemental safe space, for adolescents to engage in } \\
\text { movement and interactions based on 'kinaesthetic } \\
\text { empathy' defined as experiencing compassion and } \\
\text { kinship by observing other's movements (Momartin et } \\
\text { al., 2018). }\end{array}$ \\
\hline
\end{tabular}

Most interventions used multimodal interventions $(n=11)$ followed by music $(n=9)$, and visual art $(n=7)$ (Table 1). Length of interventions ranged from single sessions to over 30 sessions across 2 to 6 months, although in some cases information regarding duration were 
unavailable. Interventions were designed for samples drawn from populations indicative of significant experiences of trauma and therefore most employed arts as a means for participants to safely express, revisit and make meaning out of their experiences. However, while studies often worked with participants living with complex social disadvantage, the interventions did not focus on components or processes for participants to unpack landscape factors sustaining structural violence or use art as a means for activism and change.

\section{Outcomes}

\section{Feasible with predominantly positive effects}

The current scope of evidence indicates the feasibility to utilise arts-based interventions across diverse youth populations and settings with positive gains, although results are drawn from largely underpowered samples barring a few exceptions (Cortina and Fazel, 2015, Tol et al., 2014, Mueller et al., 2011, Ispanovic-Radojkovic, 2003). Controlled comparators were used in 19 studies, of which 11 used randomisation to derive results. Among the studies using an experimental design, depression and anxiety were measured using standardised instruments in 16 studies and statistically significant decrease in symptoms were reported in 12 of those studies (Kwok, 2019, Wright et al., 2006, Lindsey et al., 2018, Akandere and Demir, 2011, Dingle and Fay, 2017, Beerse et al., 2020, Cobbett, 2016, Porter et al., 2017, SmithBattle et al., 2017, Hamamci, 2006, Rahmani et al., 2016, Mueller et al., 2011, Jeong et al., 2005, Anderson et al., 2014, Kim et al., 2014, WU, 2002) .

There are no clear estimates of minimum clinically meaningful differences described in these studies. Overall, in 10 of the 16 studies that evaluated using either a RCT or nRCT design, the mean differences in depression or anxiety scores were at least more than half the standard deviation of the sample indicating potential clinical significance of the results.

Table S1 (in supplemental materials) provides an overview of the outcome measures used across studies to evaluate gains for participants. While evaluating effects through symptom reduction measures was the predominant approach, this presents challenges in understanding gains wherein living with depression or anxiety may be a response to serious trauma or constant difficulties in socio-economic-political contexts, such as areas of active conflict. Reframing gains in such scenarios towards psychosocial resources rather than deficitoriented models of trauma and mental health outcomes may be necessary (Rowe et al., 2017). 
Follow up evaluations beyond a 6-month mark were completed only in one of the studies (Hamamci, 2006). Therefore, more appropriate research methodology designed to study qualitative and quantitative outcomes longitudinally would be required to discern long term benefits.

Existing evidence is insufficient to delineate which of the identified ingredients (Table 2) are most effective and under what conditions. Among experimental studies that report statistically significant reductions on depression and anxiety symptoms, the interventions evaluated are characterised by the presence of significant peer engagement and youth participation mechanisms. Table S2 (in supplemental materials) shows an oh overview of the studies, the intervention ingredients, and benefits to participants in reducing depression or anxiety.

\section{Perceived psychological mechanisms of reported effects}

Increased self-awareness, self-efficacy, and self-esteem were reported to have protective and curative effects (Mueller et al., 2011, McDonald et al., 2015, Keller et al., 2017, Persons, 2009). In addition to reducing problem behaviours, and depression and anxiety - an increase in these domains led to improved resilience, and prosocial behaviour (Rowe et al., 2017, Mueller et al., 2011, Ispanovic-Radojkovic, 2003, Cobbett, 2016, Momartin et al., 2018). Studies reflect the need to create safe, non-judgemental spaces for young people to explore, express, and find resonance amongst peers (Thergaonkar et al., 2016, Coholic, 2011, Feng and Li, 2020, Vela et al., 2019, Gold et al., 2017, Hylton et al., 2019, Carruthers, 2014, Cherian). This improves ability to articulate mental health needs and build on internal and external strengths and resources that were undefined and unexplored previously.

\section{Youth perspectives}

Youth from India $(n=18)$ between the ages of 18-24 participated in the Sumunum arts intervention and in follow up interviews $(n=10)$ to co-produce knowledge on the effects of art engagement amongst youth with depression and anxiety. A few major themes to developing appropriate arts-based interventions emerge from their insights:

\section{Importance of early intervention}

Participants reflected on their own early encounters with mental health and placed importance on conversations and supports beginning as early as primary school for better youth mental 
health. Rather than pathologizing behaviours or emotions early, participants recommend creating opportunities for children to interrogate their experiences, express themselves freely and cultivate psychosocial resources.

"It all starts with children -- if we don't do something then, and offer support then, and take time to actually talk with and talk to them, rather than talk at or talk about them... things would be much better --- I for one would start having conversations about emotions, feelings, and how to handle difficult things -- essentially 'mental health' conversations... right from early childhood"

$-K$

"I think schools would be a great place to begin -- why not have some kind of engagement like this -- where it's fun -- not like the boring value education, which essentially just takes the moral high ground... have something where students can feel more free... where they can talk about things that are usually taboo -- like sexuality, gender identity, relationships...I think we need to normalise all emotions... not say positive and negative... but just help children, young people, students, express... express without fear"

$-T$

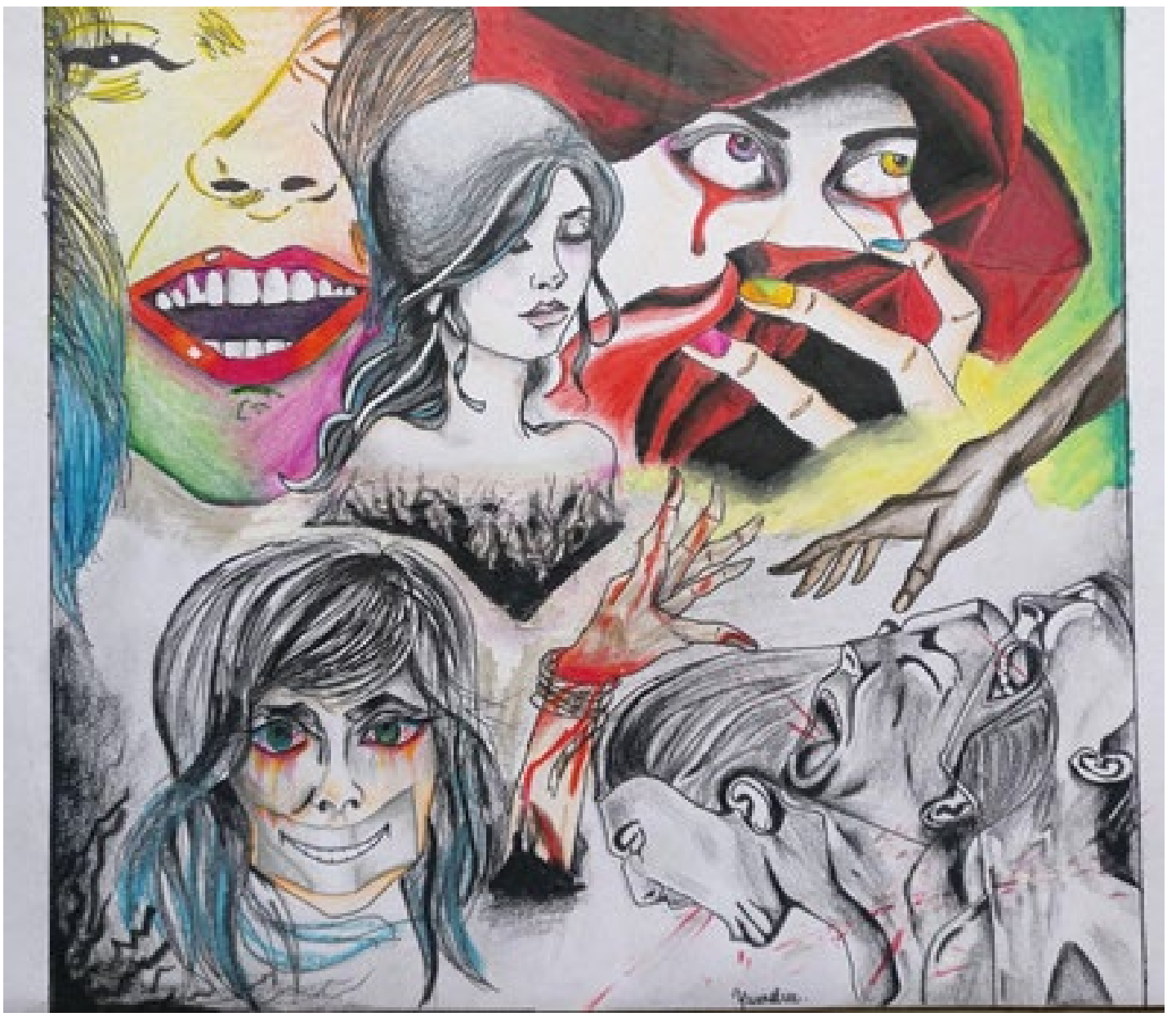

Fig. 2: Y, a youth advisor's reflection of a turbulent adolescence through art 


\section{Art as an expressive form and space free from hegemony of populist expectations}

In a forever connected world, youth are constantly inundated with bad news of the world falling apart with catastrophic social, political, economic, and environmental events. Further, these landscapes extend familial and societal pressures to conform to ideal archetypes - with constant feelings of being a failure reiterated.

"In all it's chaos, a moment of hope from the depth of our conscience tells us to keep going. Our mind tells us that it's hurting. Every inch of the body hurts to even take the next step. To dissolve into oblivion, never to come back. That no real future lies ahead except the one with masks of survival that everyone else wears. The real one where we live by what we stand for, what we dreamt about or even worked and slogged for years with no acknowledgement. We tell ourselves, it's okay, we will wait till so and so date or time and then we will take the next time. The same thought occurs at the beginning of the end of the previous one."

- A

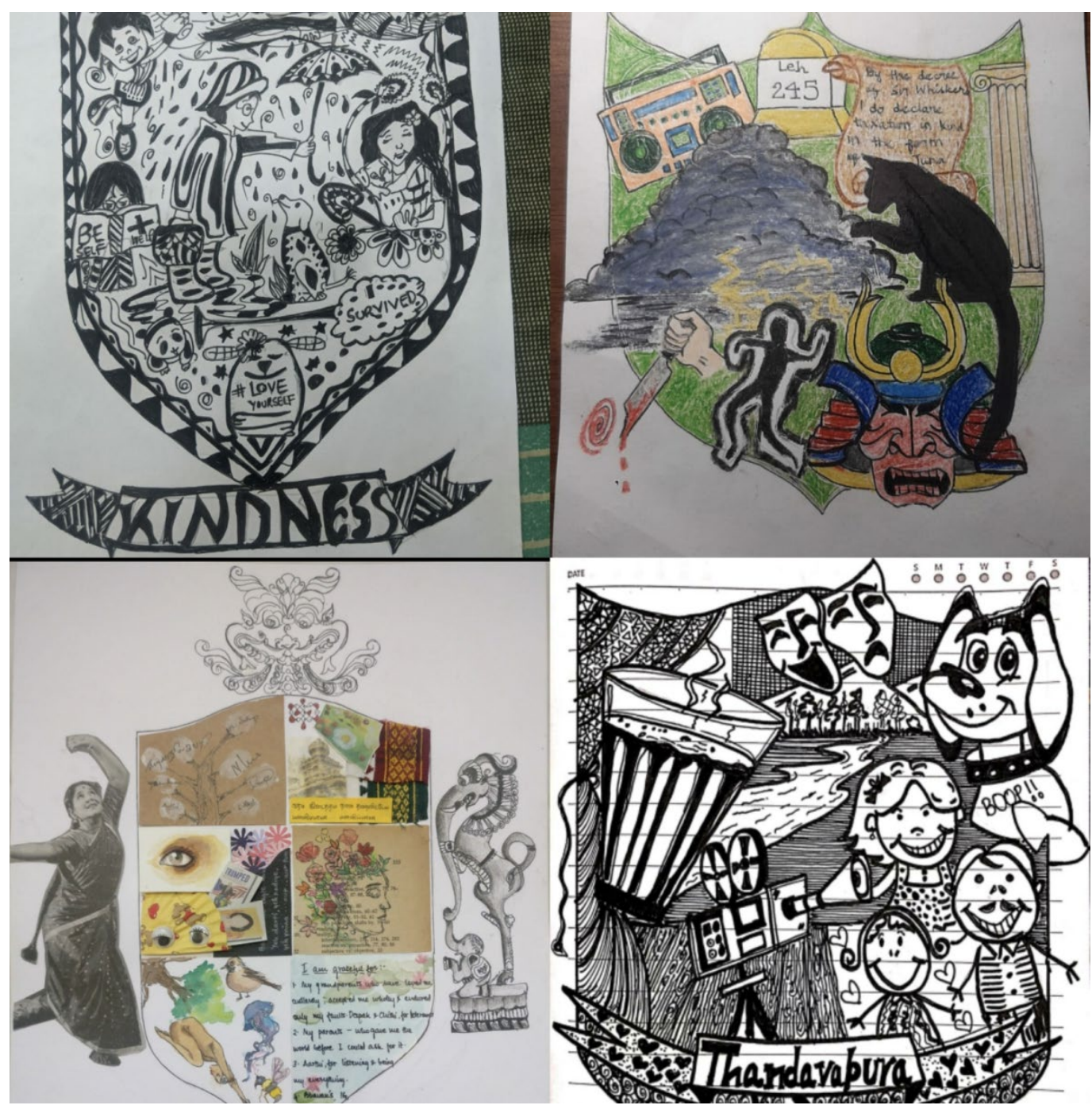

Fig. 3: Expressions of self, value orientations \& aspirations by youth advisors 
Therefore, the question for interventions to focus on is how can art support youth navigate these expectations in a world where living seems meaningless? Arts interventions allow for the expression of one's thoughts and feelings without solely relying on verbal sharing - an uncomfortable and intimidating experience for many adolescents and young adults in therapeutic settings predominantly occupied by middle-aged or older adults. This is a significant aspect contexts wherein the unequal power relations between the practitioner and patient, and carer and patient is compounded by the higher status afforded to those older, especially dominant social group affiliated (for instance upper castes in India), cisheterosexual men.

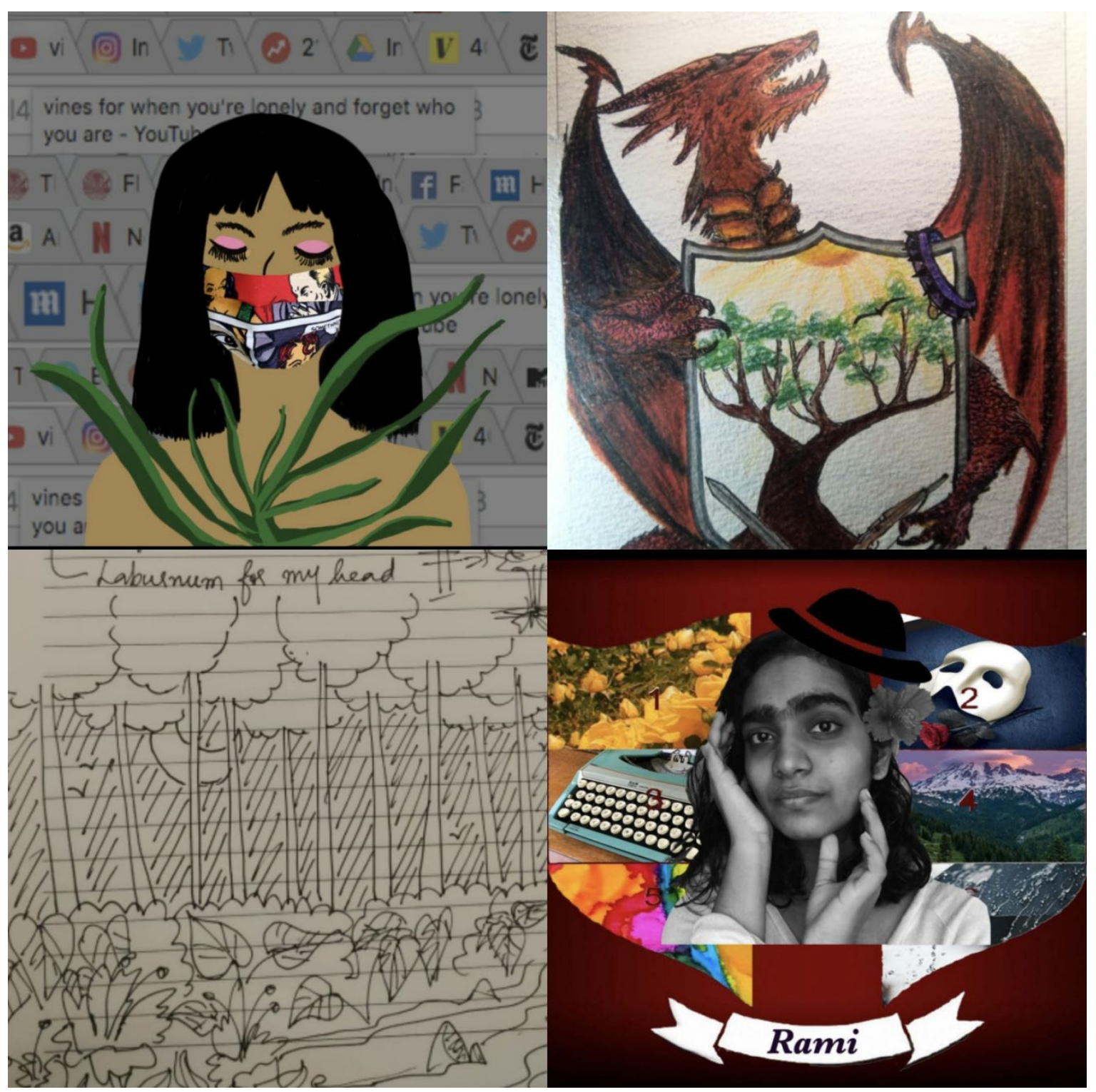

Fig. 4: Expressions of self, value orientations \& aspirations by youth advisors. 
It was observed during the intervention that participants were redefining and negotiating not only psychiatric diagnostic labels, but also medically driven understandings of emotions, health and illness shaped by biogenetic frameworks. Art exercises significantly aided in the process of 'making sense' of both oneself and one's experiences detached from societal standards of appropriate emotional responses to situations. Interactions amongst the youth advisors also show how this has led to increased self-compassion, kindness, and acceptance.

\begin{abstract}
Arts can be such a release. I don't think it's equivalent to therapy, but it should be a part of it. There's so many things the current generation has to unlearn and create new philosophies for. Arts interventions help with that. I think arts-based programmes can help us make better choices and decisions and build philosophies. It's a way to work through things that we have been told are wrong, shameful, taboo... a way to explore those experiences and feelings without 'talking' about them immediately. So, it helps to address and acknowledge these things within yourself and put it forward in a language that is meaningful to you. Seeing it out there creates a release and gives you a sense of being able to articulate your needs and concerns. $-\mathrm{K}$
\end{abstract}

\title{
Early negative experiences with mental health services
}

Most participants spoke of early negative experiences with mental health care, beginning as early as ages 11-14 years. They spoke of fan over medicalisation, a lack of importance being given to their narratives, 'being talked down to', 'being talked about - and not talked to', and overall inability to access quality affordable services.

"I felt unheard, unseen and was put off by the way medicine was prescribed as a solution." $-Y$

"School got over, I was never talked to by the psychiatrist, second session was with my family. But I did not like him in the first meet itself, he already started judging me and gave me a prescription without knowing my problem."

$-\mathrm{A}$

"incessant need to medicate, and without explanation...the first time I went to a psychiatrist, I was in school... the walls were really thin, lights bright, and my parents were made to sit with me... ... I couldn't say a thing... so many years later, when I sought someone out on my own, and I was spending over INR 1500 on the session for 45 minutes, the psychiatrist I was seeing threw me out of her office at the 40th minute, when I was in tears, and basically told me to take some medicines, and to do an assessment... honestly... i couldn't believe it"

$-P$

"my last psychiatrist used to make me cry all the time... he was just hasty, and impatient, and just not approachable or sensitive..." 


\section{Finding a tribe and a safe space for sharing}

In contrast, participants identified arts engagement as coming to a safe space where one is allowed to express freely, feels heard and finds resonating experiences, a community, or a pack.

"Being engaged in a range of activities and having this circle to come to gives me something to look forward to everyday. It's not boring -- it's not like you come to the session and only end up drawing / painting / talking every time. There's so much more! I didn't even know I could beat box or write poetry! But now I can only think in poetry! Our circle also gives me the space to be... just be... turn on the camera if I want to, keep it off, speak -- or not..."

$-S$

"Sumunum's sessions have allowed me to see myself in others, see parts of others I would like to imbibe in myself and has helped me deepen my sense of empathy. I used to think that only one-on-one help could help solve mental health issues, but these sessions remind me a lot about the power of community. Building a strong community here lets me feel like I always have a group of supportive people to come back to on difficult days. The art exercises often help me feel relieved at the end of difficult moments, and seeing others perform makes things all the more entertaining. Sumunum has helped me widen my perspectives on mental illness, community, kindness and progress. :)"

$-P$

strangers in a room

zoom in and out of each other.

illustrate and colour

the prose and poetry of the other.

a circle of unspoken words and warm hugs,

a visual prompt of storytellers and art thugs.

welcome to this community!

an opportunity

from nowhere

to find a collective journal of memory

a corner of comfort and trust -

from enchanté to festivity

so now here we sit

join us

in silence with art to discuss. 


\section{Arts as an integrated experience with core mental health services}

Despite the inadequacy of current services, participants largely converged in their perspectives of arts interventions being integrated into core mental health services. They did not view one in place of the other.

I find art to be a good release but not an all-encompassing solution. Some things need to be talked/thought through, analysed, explained, and rewritten

$-A$

Existing practitioner-focused systems view youth with depression and anxiety as people with symptoms as opposed to individuals in distress with complex unmet emotional and social needs. Despite legal protections, young people with psychosocial disabilities are routinely subject to coercive care, including involuntary institutionalisation. While arts-based interventions need to be part of core mental health services, there is an expressed need to reformulate mental health practice in user-centred terms and extricate care from coercive, top down approaches. Participants pointed out the necessity for larger social discourse, imagining and representation of mental health to shift corresponding to services to be packaged in a user centred way.

There is a lack of diversity there in terms of whose stories are shown and usually even they are "polluted by pop culture."

- $A$

Having more 'real' representation is important...maybe finding an existing web series of someone going through therapy or seeing skits / role plays can help target the misinterpretation of therapy, and the lack of knowledge present.... I also think pop-culture completely romanticises the notion of mental illness and therapy.... Like... it's a very linear narrative you know... it's like you hit a low... go to therapy, and then its happily ever after... and parents also think that if you go for therapy within a session or two you should be showing progress... but I think what they need to reflect truly is not this linear representation --- reality and the crux of therapy is that you do it again - and again - and again - and that you pick yourself up if you fall - and that its okay to do so! It becomes disheartening when you find out that it's a struggle followed by euphoria and then a happily ever after --- cos then you feel like if something goes wrong - it's all your fault... this is why 'relapse' is just so complicated - cos I feel you never really recognise progress in the true fashion then...

$-\quad Y$ 


\section{Art as a means for radical change: Structural violence and youth mental health}

As reflected in the quote at the start of this piece, youth advisors viewed art as a tool for activism and social change. Caste and gender were particularly highlighted in the Indian context as defining influences on mental health. Youth advisors also spoke of increased polarisation, emphasis on heteronormativity and lack of acceptance of gender and sexual diversity across social institutions, and environmental instability as affecting their generation's mental health significantly. Art was in this context seen as a tool to de-pathologize their distress and instead shift focus towards these underlying institutional forces.

"as an MBC*2 girl, darker skinned, and that too with acne -- growing up was a nightmare - to this
day.... I have to keep my lights off around me just because I don't like to see myself in the mirror..
sometimes, when I have to be on stage, it's so challenging because I don't like anybody doing
my makeup... it's a miracle I even got back on stage again... once when I was younger, I was
told I couldn't be the host for the annual day because the colour theme for that year would clash
with my skin tone.... these things ring in my ears even today... imagine being 12 and hearing
that your skin doesn't match with some fabric..."
- A

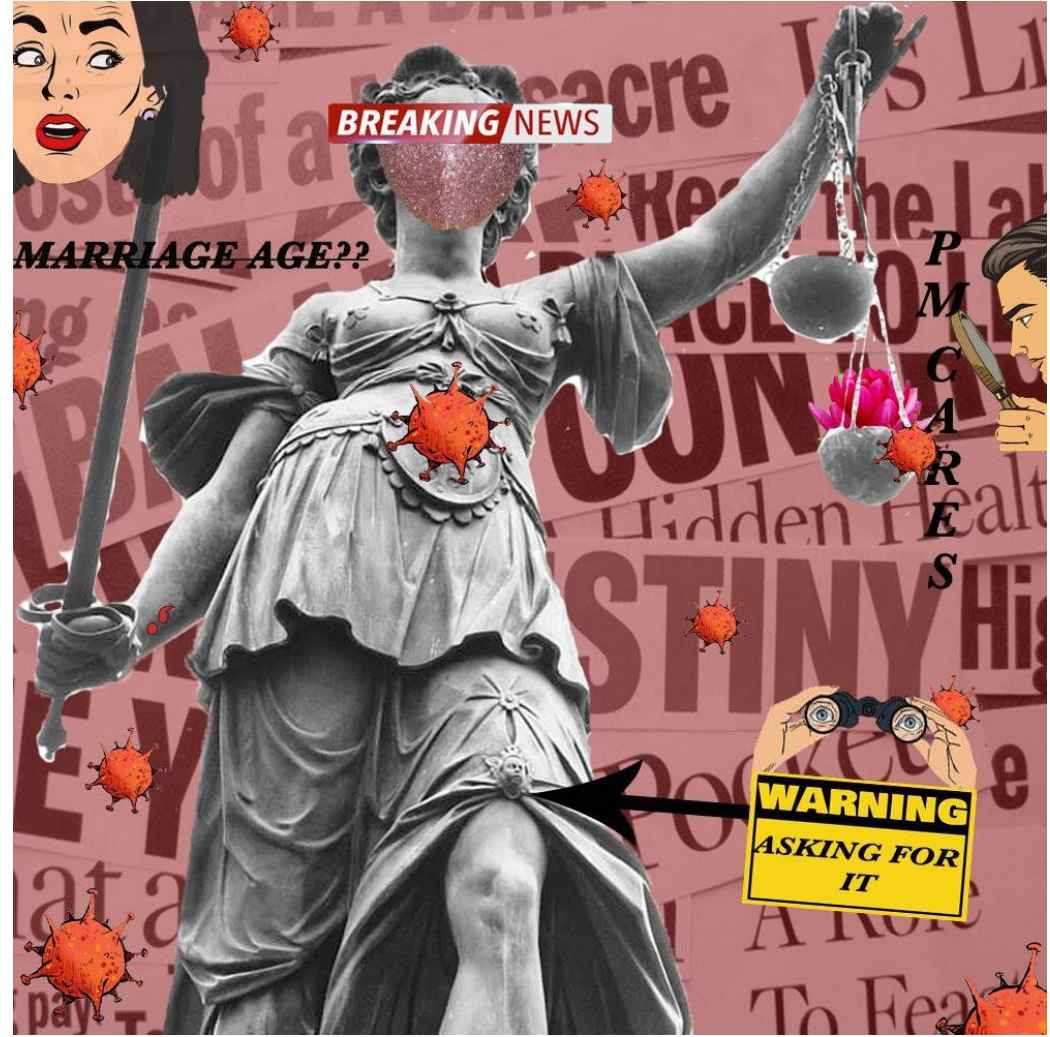

Fig. 5: Youth advisor's artwork in response to deep-rooted patriarchal systems and recent celebrity death by suicide.

\footnotetext{
${ }^{2} \mathrm{MBC}$ refers to a group of communities called the Most Backward Castes. They are traditionally marginalized, and ostracized communities.
} 


\section{Key insights}

The aim of the participatory insight analysis was to synthesize existing research on arts engagement amongst youth with depression and/or anxiety. It sought to discern the influence of theatre and arts-based interventions amongst this population. Understanding how arts interventions are deployed and specific populations for whom arts interventions work / do not work was of particular significance. The scoping review revealed emerging, promising evidence for the usage of arts as treatment and preventive interventions for youth with depression and anxiety.

\section{Art based interventions - essential ingredients}

A typology of eight essential ingredients was framed based on the existing evidence (Table 2). However, there was insufficient evidence to indicate the relative importance and effectiveness of each ingredient due to the lack of uniformity amongst the interventions, study populations, research methods, and outcome measures used. In some studies interventions were not adequately described; intervention modalities, session plans and theoretical approaches were not available. Preliminary evidence indicates that a combination of these ingredients are effective in reducing levels of anxiety and depression and enhancing protective factors amongst youth with mild to moderate anxiety and depression, trauma, emotional and behavioural difficulties, and exposure to adverse life events. Participant feedback from our own intervention revealed all eight ingredients listed to be critical, with specific emphasis on the need for creation of a safe space that enables greater meaning making, is multi-modal, participatory, and peer-led, and improvisational. The current evidence is not sufficient to determine effectiveness of arts interventions for youth with severe depression. Some systematic reviews reveal statistically significant effects of art engagement on reduction of anxiety and depression; however, it remains unclear as to whether this is the effect of the intervention, access to allied services, or other confounders and covariates. In the same vein, it is unclear whether lack of effectiveness is associated with the intervention, in studies that are statistically insignificant.

\section{Art interventions in the Global South}

Despite rich cultural heritage, there is limited evidence on art interventions emerging from the Global South. It is particularly sparse in the field of youth mental health. The little evidence 
from the scoping review indicates statistically significant gains of arts-based interventions on reduction of depression and anxiety amongst youth from vulnerable backgrounds - particularly those suffering trauma, parental bereavement, and abuse. Further, there is evidence of improvement in self-efficacy, self-esteem, self-awareness, hope and other protective factors.

In most regions of the Global South, mental health care services remain predominantly biomedical. A comprehensive, tiered referral system does not exist in most regions. In LMICs like India there are no targeted child and adolescent mental health services. Given the resource scarcity, and unyielding structural barriers in most countries of the Global South, innovative, locally contextualized approaches are critical. Approaches focused on offering integrated care through task shifting and non-health pathways that draw from indigenous knowledge must be encouraged. In this context, arts-based interventions are particularly relevant. They offer non-stigmatising care, embedded in local cultural practices. Further, as pointed out by our youth advisors, 'mental health nomenclature' is different in the Global South - words like 'depression', 'anxiety', 'recovery', and 'relapse' have varying connotations, and are shrouded in stigma. Using arts-based practices allows for the development of personally meaningful vocabularies that may be used to articulate mental health needs. Additionally, given the deep rooted racial, caste, class, and gender discrimination, mental health issues like depression and anxiety are the result of deep rooted oppressive, humiliating, and discriminatory practices. In this context, arts practices ensure the creation of a non-threatening, safe space for expression, such that distress can be culturally framed through a social justice lens. One such example is Jadhav's use of the term social defeat to situate the social suffering of Dalit students experiencing psychological and suicidal distress within elite educational institutions due to institutional casteism (Jadhav et al., 2016) with preliminary findings from a study employing such a lens supporting the need for culturally resonant care (Jadhav, 2019).

\section{Necessity to reorient the biomedical gaze}

The mental health construct in studies reviewed was predominantly biomedical, and oriented to DSM nosologies. There was a strong emphasis on 'cure', 'successful treatment' and interventions aimed at extinguishing symptoms (Rahmani et al., 2016). Little attention was paid towards distress and user-led perceptions and experiences of mental health concerns. This concern was echoed by our youth advisors as well, who made several references to having been 'dismissed' or feeling 'invalidated' by mental health professionals. Concepts like stress and anxiety (though related), were sometimes used interchangeably, and revealed inconsistencies and lack of conceptual clarity. There was an apparent lack of insight into social 
determinants. Majority of the studies reviewed made no mention of socio-economic status, gender, class, race, caste, and other structural barriers that significantly affect mental wellbeing. This was surprising particularly in studies that had been conducted amongst youth with high needs - such as with refugee children and adolescents, where generalisations about academic performance, and conduct were made without comprehensively framing the social context or personal experiences that may influence poor outcomes (Momartin et al., 2018).

Only a handful of studies adopted a broader, social construction of mental health, with a psychological distress orientation. These studies emphasised the role of social and familial support, and the effects of caregiver instability, sibling dispersion, inequity, unequal treatment, violence, multiple bereavement, deprivation, and uncertainty on mental health and wellbeing outcomes (Ispanovic-Radojkovic, 2003, Mueller et al., 2011, Lange-Nielsen et al., 2012).

\section{Art concept - lack of intersectoral collaboration}

The conceptualisation of art engagement and what it encapsulates was varied. Theoretical frameworks used to formulate the art concept drew from somatic practices, trauma informed approaches, kinaesthetic empathy, expression and narrative approaches, and mindfulnessbased techniques (Mueller et al., 2011, Chen, 2020, Keller et al., 2017, Vela et al., 2019, Gold et al., 2017). Arts based interventions were largely used for young people with mild to moderate depression \& anxiety. We did not come across any evidence of use for those with severe illness presentations.

Most arts interventions were conceptualized by mental health researchers and arts-based therapists and not by arts practitioners. While a large volume of work initiated by artists exists, they are largely undocumented in scientific literature, and not considered interventions (Crossley et al., 2019). For e.g. the work of Geese Theatre Company and Excavate Theatre in the UK; Jana Sanskriti, Artroom, Jagran Theatre Group, \& Theatre Y in India; Brainstorm Productions in Australia are but few organisations that are led by arts practitioners who engage in arts practices for mental health \& wellbeing. Several smaller local art, culture and heritage organisations lack the research knowledge to incorporate effective designs and evaluations into their programmes. They carry valuable community knowledge, and often work with individuals from vulnerable groups through various modalities (exhibitions / performances / participation through workshops / cultural events etc.) however, have limited access to funding $\&$ grants to build strong evidence-based programmes. 
Evidence revealed that often art that was just 'integrated' into therapeutic frameworks, and therefore the art engagement sessions inherited the medical hegemony and gaze. This was also reflected in the approaches to monitoring and evaluation that were primarily quantitative \& behavioural outcome driven rather than qualitative \& holistic to measure process engagement and tacit learnings as well.

\section{Lack of robust study designs}

Unfortunately, the quality of evidence was largely mediocre. Most measured only mental health outcomes to assess intervention quality - but did not adequately explore appropriateness, and acceptability. Further, there were very few process evaluations. Very few mentioned attendance rates, or carried qualitative information on participant experiences and feedback, or implementation constraints. Very few evaluated the arts-based processes underlying the intervention. Particularly in studies from the Global South, reporting of randomisation strategy, demographic data, recruitment process, power analysis, researcher positionality (in qualitative studies) and funding information goes unreported in several studies.

\section{Conspicuous absence of youth voices}

There was a uniform lack of youth participation in current evidence. Findings were predominantly researcher assertions, and not led by young people. Evidence of youth inclusion was only seen at the participant level, through qualitative interviews or focus groups. We did not come across any comprehensive programmes that included young people through the process of programme conceptualisation, execution, and evaluation. Most interventions in the evidence reviewed were short term, with no follow up measures. There is an urgent need for more youth led evaluation of arts-based interventions.

The overall lack of consistency in approach, definition and conceptualization made it challenging to infer specifics. We see a need to develop contextual and user-led definitions of mental health, mental illness, and arts engagement. The primarily biomedical lens also affected our ability to specify with certainty as to 'whom the intervention works for, where and why', however we inferred with context, and drew from our own experience, to the best of our abilities 


\section{Where do arts interventions work?}

Arts interventions had strong positive outcomes amongst young people with experiences of trauma. Trauma in this context was defined as experiencing or witnessing violence (sexual / physical / emotional), displacement, war, and conflict (post active war/conflict periods), discrimination, and other adverse life events.

Research posited its success in this context because of the more humane framework that the arts provide, within which young people can make sense of the events and foster greater sense of hope and aspirational thinking (Ispanovic-Radojkovic, 2003). The sensory focus and nature of art engagements offered an opportunity to narrate and explore traumatic memories and difficult emotions (such as anger, shame, hate, and guilt) without explicitly 'talking', thereby removing fear of judgement (Vela et al., 2019, Ramirez et al., 2020). This expression paved the way for a deeper understanding and processing of traumatic events, clearer articulation of mental health needs, and stronger meaning making schemas.

Group activities that foster a safe, non-competitive environment, mentoring, self-compassion \& personal honour, and a space to explore and build value drivers experientially through artsbased activities had greater positive engagement experiences and improved outcomes (Momartin et al., 2018). Evidence indicated that arts interventions were particularly effective in improving self-awareness, self-efficacy, and self-esteem. Improvements in these domains, particularly self-efficacy had a positive impact on building resilience and improved problem solving over time. Group interventions played a significant role in developing prosocial behaviour and reducing problems with peers. Art engagements were also effective as treatment interventions in school settings (Cortina and Fazel, 2015, WU, 2002, Kim et al., 2014). They have potential to be used as tools for prevention and promotion of mental health amongst children and adolescents. Our youth advisors also recommend inclusion of mental health conversations, and formalised engagement sessions from an early age. Barring when used as treatment interventions in areas of active conflict, evidence globally indicates that school-based arts interventions promote significant improvements in mental health outcomes amongst youth. The Art Room - a UK based intervention revealed a strong improvement in emotional and behavioural outcomes with a $41 \%$ reduction in the number of students meeting criteria for 'clinical level difficulties', and $87.5 \%$ improvement in moods and feelings post intervention (Cortina and Fazel, 2015). 


\section{Where are they not feasible?}

Evidence indicated that school-based arts interventions were not an appropriate treatment method for PTSD, depression, and anxiety amongst young people in areas of active conflict (Tol et al., 2014). In some geographies and populations such as, among girls in Indonesia, boys with less ongoing trauma exposure in Sri Lanka, and children with both parents alive in Burundi there had been reductions in symptoms of depression and anxiety. However, this was not seen uniformly in other regions like Nepal or occupied Palestine territories, and in fact was associated with unfavourable effects on PTSD symptoms in Sri Lankan girls, and older children in occupied Palestine territories (Jordans et al., 2013). A manualised expressive writing intervention used amongst adolescents in Gaza indicated a significant elevation of depressive symptoms 19 days after the intervention was deployed (Lange-Nielsen et al., 2012). While this could be attributed to the processing and resurfacing of trauma memories, the elevation in depressive symptoms highlights the need to exercise great caution while tackling psychological suffering in war-torn regions. In these regions, the WHO mandated guidelines recommend CBT and EMDR for treatment of PTSD amongst adolescents (Tol et al., 2013). Further, no therapeutic intervention - arts based, school based, or otherwise - can be effective if children and young people are not assured basic necessities of shelter, sanitation, safety, and dignity.

It is interesting to note however that the same school-based arts interventions that were not suitable treatment options, had significant potential as preventive interventions. They were shown to strengthen and build resilience processes amongst children and adolescents affected by conflict. The same intervention had improved outcomes on hope, positive coping, social support, pro-social behaviour, and functioning across Indonesia, Sri Lanka, Nepal and occupied Palestinian territories. Implementing a school-based arts intervention like this, without trauma elements, but with greater familial and community involvement may prove to have strong protective effects (Ager et al., 2011).

Viewing these findings through the ecological resilience framework could provide a holistic view of children's mental health by accounting for the resources and strengths available to them personally and through their social contexts at the family, peer, and community levels. These strengths and resources were strong predictors of intervention effects (Brom et al., 2008, Tol et al., 2010). Clarity in scope and aims of the intervention - i.e. to be used for prevention or treatment; and detailed assessments to identify the most socially vulnerable youth is critical. Evidence indicated that implementation in more homogenous groups yielded positive preventive effects and protective factors for children and youth in more stable conditions (Tol et al., 2010). 
While there is debate on whether school based mental health programmes should be delivered universally, only for indicated populations, or in combination, for both - evidence for the efficacy of embedding mental health programmes in schools is promising (Wolpert et al., 2013).

\section{Study limitations}

There are a few methodological limitations that need to be considered in this study. Firstly, the heterogeneity in the nature of interventions, studies, outcomes, measures used, and populations made it challenging to interpret findings with specificity. Secondly, it was difficult to hone in on the specific age range as studies either included much younger children, or much older adults. To reduce risk of bias we have been flexible with the lower age range and placed a hard stop at the upper end since that population would likely be included in the systematic reviews. The quality of studies overall were mediocre. They were largely underpowered, with medium to high risk of bias. Furthermore, we did not cover the entire spectrum of all art interventions / engagements as that would have been too broad to effectively complete within our study timeframe. Thus, more passive engagements such as visits to public arts spaces, cultural sites, passive music listening, reading etc. were excluded. 


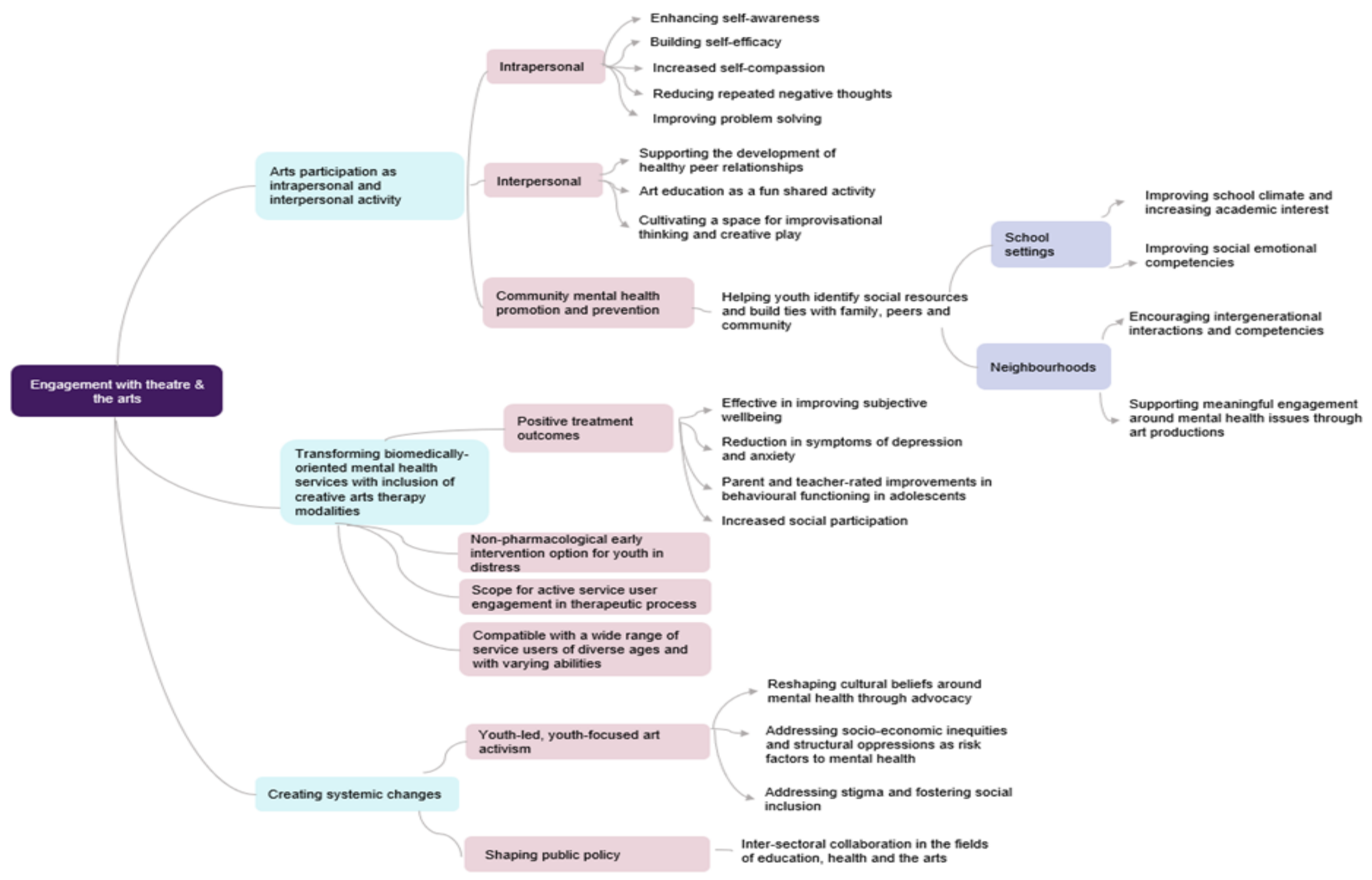

Fig. 6: Arts engagement: Proposed mechanism of action based on findings of insight analysis 


\section{Recommendations for future practice and research}

Based on the evidence reviewed, and our experience as arts and mental health professionals who are committed to a more holistic integration of arts in mental health and social development practice, we recommend the following for future practice and research.

\section{Recommendations for practice}

Arts interventions show promise as tools for prevention and mental health promotion. Stronger integration of arts practices into educational systems will systematically aid in development of protective factors. Evidence of more pronounced impact in children of primary school age calls for early intervention to address mental health difficulties before they become entrenched and less responsive to intervention.

Art is a strong catalyst to spur greater youth participation in the creation of responsive mental health services. Arts participation can be used as a medium to mitigate stigma attached to mental distress and foster social inclusion by facilitating meaningful social dialogue.

Art-based approaches, when involving active engagement by participants in group or community settings, can attenuate systemic power relations within health systems or even positively transform such relations to reduce health inequalities.

Art can be used for mental health advocacy led by service users and can also be used to humanise the patient/clinician interaction and relationship (Furman et al., 2006).

Arts' rootedness in culture offers an opportunity to support youth with culturally relevant services in non-clinical environments, which may be perceived as less stigmatising.

Evidence suggests that greater collaboration between applied arts practitioners and mental health researchers and professionals would be advantageous. This will foster greater transparency and innovation in intervention approaches, research methodology \& evaluation plans. Such innovation may necessitate creative dialogues between disciplines as well as clearer agreements over shared terminologies and what may constitute evidential legitimacy.

A two-tiered system of evaluation is necessary - (1) process indicators and measures to evaluate extent and quality of engagement in interventions (2) mental health outcome indicators. 
The existing evidence does not provide enough clarity on effectiveness of arts interventions for youth with severe illness presentations. There is a need for more robust research into arts interventions for young people with moderate to severe depression and anxiety.

More focused research on the effects of arts engagement, art therapy, and arts participation could be beneficial as all three have slightly differing modalities.

Researchers should consider whether mechanisms aimed at treating mental health issues are the same as those that should be targeted to prevent them. Further studies could consider focusing on specific populations and conduct longer follow up evaluations to allow more time for possible preventive effects to be seen.

Consideration of how existing 'evidence-based interventions' which are often tested in highly resourced, controlled research settings can be effectively disseminated and implemented pragmatically in real-world health and social care systems 
Create interventions aimed at providing mental health support for children right from primary school. These interventions can be arts based because that makes it engaging. It can be located within the educational system; however, they need to incorporate a holistic approach and offer capacity building support for teaches, and parents as well.

Incorporate arts-based services as a part of existing mental health care services. However, with specific focus on India - access to mental healthcare services are already very poor, and unaffordable particularly for young people. Creating more subsidised services, and perhaps services that can be accessed in groups, and in non-clinical settings could be more affordable, and relatable.

Work specifically with parents on incorporating conversations around mental health, understanding emotion, and normalising distress.

Involve more young people in creation of mental health services.

Create more engaging, participatory mental health awareness programmes. Current programmes are too didactic - and do not effectively capture youth realities, and complexities of growing up in a rapidly changing world. Build from youth narratives and create public engagement art pieces that will 'speak to people', force them to question their own biases, and look deeper inwards.

\section{Conclusion}

This participatory insight analysis focused on gaining an understanding of "where, what art interventions work, for whom, and how" and vice-versa. Results indicate that art interventions are suitable for deployment across clinical and educational settings, and may be used for prevention, mental health promotion and treatment. Youth voices from arts engagement sessions conducted through the current study substantiate the findings of the scoping review. Early results also advocate for a comprehensive approach to youth mental health wherein existing mental health services are strengthened through greater intersectoral collaboration between health, education, and arts practices. 


\section{References}

AGER, A., AKESSON, B., STARK, L., FLOURI, E., OKOT, B., MCCOLLISTER, F. \& BOOTHBY, N. 2011. The impact of the school-based Psychosocial Structured Activities (PSSA) program on conflict-affected children in northern Uganda. Journal of child psychology and psychiatry, 52, 1124-1133.

AKANDERE, M. \& DEMIR, B. 2011. The effect of dance over depression. Collegium antropologicum, 35, 651-656.

ANDERSON, A. N., KENNEDY, H., DEWITT, P., ANDERSON, E. \& WAMBOLDT, M. Z. 2014. Dance/movement therapy impacts mood states of adolescents in a psychiatric hospital. The Arts in Psychotherapy, 41, 257-262.

BEERSE, M. E., VAN LITH, T. \& STANWOOD, G. 2020. Therapeutic psychological and biological responses to mindfulness-based art therapy. Stress and Health.

BROM, D., PAT-HORENCZYK, R. \& FORD, J. D. 2008. Treating traumatized children: Risk, resilience and recovery, Routledge.

CARRUTHERS, E. 2014. Safety, Connection, Foundation: Single-Session Individual Music Therapy With Adolescents. Canadian Journal of Music Therapy, 20.

CHEN, S. 2020. INTERVENTION EFFECT OF MUSIC EDUCATION ON MENTAL HEALTH OF COLLEGE STUDENTS. Revista Argentina de Clínica Psicológica, 29, 704-709.

CHERIAN, R. M. Using Superheroes in Art Therapy through Counselling for Adolescents Boys in Conflict with Law: Illustrations from Juvenile Home in Ernakulam, Kerala.

COBBETT, S. 2016. Reaching the hard to reach: Quantitative and qualitative evaluation of school-based arts therapies with young people with social, emotional and behavioural difficulties. Emotional and Behavioural Difficulties, 21, 403-415.

COHOLIC, D. A. Exploring the feasibility and benefits of arts-based mindfulness-based practices with young people in need: Aiming to improve aspects of self-awareness and resilience. Child \& Youth Care Forum, 2011. Springer, 303-317.

COLLINS, P. Y., PATEL, V., JOESTL, S. S., MARCH, D., INSEL, T. R., DAAR, A. S., BORDIN, I. A., COSTELLO, E. J., DURKIN, M. \& FAIRBURN, C. 2011. Grand challenges in global mental health. Nature, 475, 27-30.

CORTINA, M. A. \& FAZEL, M. 2015. The Art Room: An evaluation of a targeted school-based group intervention for students with emotional and behavioural difficulties. The arts in psychotherapy, 42, 35-40.

COULTER, A. \& GORDON-NESBITT, R. 2016. All Party Parliamentary Group on Arts, Health and Wellbeing: submission to the DCMS white paper consultation.

CROSSLEY, M., BARRETT, A., BROWN, B. J., COOPE, J. \& RAGHAVEN, R. 2019. a systematic review of applied theatre practice in the indian context of mental health, resilience and wellbeing. Applied Theatre Research, 7, 211-232.

DINGLE, G. A. \& FAY, C. 2017. Tuned In: The effectiveness for young adults of a group emotion regulation program using music listening. Psychology of Music, 45, 513-529.

FANCOURT, D. 2017. Arts in Health: Designing and researching interventions, Oxford University Press.

FANCOURT, D. \& FINN, S. 2019. What is the evidence on the role of the arts in improving health and well-being?

FANIAN, S., YOUNG, S. K., MANTLA, M., DANIELS, A. \& CHATWOOD, S. 2015. Evaluation of the $\mathrm{K}$ ts' iihtła ("We Light the Fire") Project: building resiliency and connections through strengths-based creative arts programming for Indigenous youth. International journal of circumpolar health, 74, 27672.

FENG, Y. \& LI, Z. 2020. Empirical analysis on the intervention of music therapy on mental health of college students. Revista Argentina de Clínica Psicológica, Vol. XXIX, №2, 1272-1281. 
FURMAN, R., COLLINS, K., LANGER, C. \& BRUCE, E. A. 2006. Inside a provider's perspective: Using practitioner poetry to explore the treatment of persons with mental illness. The Arts in psychotherapy, 33, 331-342.

GOLD, C., SAARIKALLIO, S., CROOKE, A. H. D. \& MCFERRAN, K. S. 2017. Group music therapy as a preventive intervention for young people at risk: Cluster-randomized trial. The Journal of Music Therapy, 54, 133-160.

GORE, F. M., BLOEM, P. J., PATTON, G. C., FERGUSON, J., JOSEPH, V., COFFEY, C., SAWYER, S. M. \& MATHERS, C. D. 2011. Global burden of disease in young people aged 10-24 years: a systematic analysis. The Lancet, 377, 2093-2102.

GREIG, N. 2008. Young people, new theatre: a practical guide to an intercultural process, Routledge.

GULLIVER, A., GRIFFITHS, K. M. \& CHRISTENSEN, H. 2010. Perceived barriers and facilitators to mental health help-seeking in young people: a systematic review. $B M C$ psychiatry, 10, 113.

HACKING, S., SECKER, J., KENT, L., SHENTON, J. \& SPANDLER, H. 2006. Mental health and arts participation: the state of the art in England. The journal of the Royal Society for the Promotion of Health, 126, 121-127.

HAMAMCI, Z. 2006. Integrating psychodrama and cognitive behavioral therapy to treat moderate depression. The Arts in Psychotherapy, 33, 199-207.

HEENAN, D. 2006. Art as therapy: an effective way of promoting positive mental health? Disability \& Society, 21, 179-191.

HYLTON, E., MALLEY, A. \& IRONSON, G. 2019. Improvements in adolescent mental health and positive affect using creative arts therapy after a school shooting: A pilot study. The Arts in Psychotherapy, 65, 101586.

ISPANOVIC-RADOJKOVIC, V. 2003. Youth clubs: Psychosocial intervention with young refugees. Intervention: International Journal of Mental Health, Psychosocial Work \& Counselling in Areas of Armed Conflict, 1, 38-44.

JADHAV, S. 2019. Developing an anthropological psychiatry strategy for culturally framed social defeat affecting Dalits in higher education in India [Poster].

JADHAV, S., MOSSE, D. \& DOSTALER, N. 2016. Minds of caste-Discrimination and its affects. Anthropology Today, 32, 1-2.

JEONG, Y.-J., HONG, S.-C., LEE, M. S., PARK, M.-C., KIM, Y.-K. \& SUH, C.-M. 2005. Dance movement therapy improves emotional responses and modulates neurohormones in adolescents with mild depression. International journal of neuroscience, 115, 17111720.

JORDANS, M. J., TOL, W. A., SUSANTY, D., NTAMATUMBA, P., LUITEL, N. P., KOMPROE, I. H. \& DE JONG, J. T. 2013. Implementation of a mental health care package for children in areas of armed conflict: a case study from Burundi, Indonesia, Nepal, Sri Lanka, and Sudan. PLoS Med, 10, e1001371.

KAGAN, C., SIXSMITH, J., SIDDIQUEE, A., BOL, S., LAWTHOM, R. \& KILROY, A. 2005. Community psychology and participatory arts: well-being and creativity.

KELLER, S. N., AUSTIN, C. G. \& MCNEILL, V. 2017. A theater intervention to promote communication and disclosure of suicidal ideation. Journal of applied communication research, 45, 294-312.

KIM, S., KIM, G. \& KI, J. 2014. Effects of group art therapy combined with breath meditation on the subjective well-being of depressed and anxious adolescents. The Arts in psychotherapy, 41, 519-526.

KUMAR, S. 2004. ACTing: the pandies' theatre of Delhi. TDR/The Drama Review, 48, 79-95.

KWOK, S. Y. 2019. Integrating positive psychology and elements of music therapy to alleviate adolescent anxiety. Research on Social Work Practice, 29, 663-676.

LANGE-NIELSEN, I. I., KOLLTVEIT, S., THABET, A. A. M., DYREGROV, A., PALLESEN, S., JOHNSEN, T. B. \& LABERG, J. C. 2012. Short-term effects of a writing intervention among adolescents in Gaza. Journal of Loss and Trauma, 17, 403-422. 
LINDSEY, L., ROBERTSON, P. \& LINDSEY, B. 2018. Expressive arts and mindfulness: Aiding adolescents in understanding and managing their stress. Journal of Creativity in Mental Health, 13, 288-297.

LUND, C., DE SILVA, M., PLAGERSON, S., COOPER, S., CHISHOLM, D., DAS, J., KNAPP, M. \& PATEL, V. 2011. Poverty and mental disorders: breaking the cycle in low-income and middle-income countries. The lancet, 378, 1502-1514.

LUND, C., TOMLINSON, M. \& PATEL, V. 2016. Integration of mental health into primary care in low-and middle-income countries: the PRIME mental healthcare plans. The British Journal of Psychiatry, 208, s1-s3.

MCDONALD, J., CODREA, A. \& GAVIN, B. 2015. A pilot music group for young people attending a community Child and Adolescent Mental Health Service. Irish journal of psychological medicine, 32, 259-264.

MOHER, D., LIBERATI, A., TETZLAFF, J., ALTMAN, D. G. \& GROUP, P. 2009. Preferred reporting items for systematic reviews and meta-analyses: the PRISMA statement. PLoS med, 6, e1000097.

MOKDAD, A. H., FOROUZANFAR, M. H., DAOUD, F., MOKDAD, A. A., EL BCHERAOUI, C., MORADI-LAKEH, M., KYU, H. H., BARBER, R. M., WAGNER, J. \& CERCY, K. 2016. Global burden of diseases, injuries, and risk factors for young people's health during 1990-2013: a systematic analysis for the Global Burden of Disease Study 2013. The Lancet, 387, 2383-2401.

MOMARTIN, S., DA SILVA MIRANDA, E., AROCHE, J. \& COELLO, M. 2018. Resilience building through alternative intervention:'STARTTS "Project Bantu Capoeira Angola"; On the road to recovery. Intervention, 16, 154.

MUELLER, J., ALIE, C., JONAS, B., BROWN, E. \& SHERR, L. 2011. A quasi-experimental evaluation of a community-based art therapy intervention exploring the psychosocial health of children affected by HIV in South Africa. Tropical Medicine \& International Health, 16, 57-66.

PATEL, V. 2007. Mental health in low-and middle-income countries. British Medical Bulletin, 81, 81-96.

PATEL, V., FLISHER, A. J., HETRICK, S. \& MCGORRY, P. 2007. Mental health of young people: a global public-health challenge. The Lancet, 369, 1302-1313.

PATEL, V., GOEL, D. S. \& DESAI, R. 2009. Scaling up services for mental and neurological disorders in low-resource settings. International health, 1, 37-44.

PERSONS, R. W. 2009. Art therapy with serious juvenile offenders: A phenomenological analysis. International Journal of Offender Therapy and Comparative Criminology, 53, 433-453.

PORTER, S., MCCONNELL, T., MCLAUGHLIN, K., LYNN, F., CARDWELL, C., BRAIDEN, H. J., BOYLAN, J., HOLMES, V., GROUP, M. I. M. S. \& ROGAN, S. 2017. Music therapy for children and adolescents with behavioural and emotional problems: A randomised controlled trial. Journal of Child Psychology and Psychiatry, 58, 586-594.

RAHMANI, M., SAEED, B. B. \& AGHILI, M. 2016. Integrating effect of art and music therapy on depression in adolescents. Journal of Educational Sciences and Psychology, 6.

RAMIREZ, K., HAEN, C. \& CRUZ, R. F. 2020. Investigating Impact: The Effects of SchoolBased Art Therapy on Adolescent Boys Living in Poverty. The Arts in Psychotherapy, 101710.

ROWE, C., WATSON-ORMOND, R., ENGLISH, L., RUBESIN, H., MARSHALL, A., LINTON, K., AMOLEGBE, A., AGNEW-BRUNE, C. \& ENG, E. 2017. Evaluating art therapy to heal the effects of trauma among refugee youth: The Burma art therapy program evaluation. Health promotion practice, 18, 26-33.

SASSI, F. 2006. Calculating QALYS, comparing QALY and DALY calculations. Health policy and planning, 21, 402-408.

SECKER, J., HACKING, S., KENT, L., SHENTON, J. \& SPANDLER, H. 2009. Development of a measure of social inclusion for arts and mental health project participants. Journal of Mental Health, 18, 65-72. 
SMITHBATTLE, L., CHANTAMIT-O-PAS, C., FREED, P., MCLAUGHLIN, D. \& SCHNEIDER, J. K. 2017. Moms growing together: Piloting action methods and expressive arts in a therapeutic group for teen mothers. Journal of Child and Adolescent Psychiatric Nursing, 30, 72-79.

SPANDLER, H., SECKER, J., KENT, L., HACKING, S. \& SHENTON, J. 2007. Catching life: The contribution of arts initiatives to recovery approaches in mental health. Journal of psychiatric and mental health nursing, 14, 791-799.

STARICOFF, R. L. 2004. Arts in health: a review of the medical literature. Arts Council England London.

TARR, J., GONZALEZ-POLLEDO, E. \& CORNISH, F. 2018. On liveness: using arts workshops as a research method. Qualitative Research, 18, 36-52.

THERGAONKAR, N., TIWARI, N., JAIN, R. \& BHULLAR, H. 2016. Arts based therapy for survivors of trauma and abuse in government and NGO-run children's homes for girls in Delhi. Save the Children.

TOL, W. A., BARBUI, C. \& VAN OMMEREN, M. 2013. Management of acute stress, PTSD, and bereavement: WHO recommendations. Jama, 310, 477-478.

TOL, W. A., KOMPROE, I. H., JORDANS, M. J., NDAYISABA, A., NTAMUTUMBA, P., SIPSMA, H., SMALLEGANGE, E. S., MACY, R. D. \& DE JONG, J. T. 2014. Schoolbased mental health intervention for children in war-affected Burundi: a cluster randomized trial. BMC medicine, 12, 56.

TOL, W. A., REIS, R., SUSANTY, D. \& DE JONG, J. T. 2010. Communal violence and child psychosocial well-being: qualitative findings from Poso, Indonesia. Transcultural Psychiatry, 47, 112-135.

VELA, J. C., SMITH, W. D., RODRIGUEZ, K. \& HINOJOSA, Y. 2019. Exploring the Impact of a Positive Psychology and Creative Journal Arts Intervention with Latina/o Adolescents. Journal of Creativity in Mental Health, 14, 280-291.

VIJAYAKUMAR, L., JOHN, S., PIRKIS, J. \& WHITEFORD, H. 2005. Suicide in developing countries (2) risk factors. Crisis, 26, 112-119.

WHITTEMORE, R. \& KNAFL, K. 2005. The integrative review: updated methodology. Journal of advanced nursing, 52, 546-553.

WOLPERT, M., HUMPHREY, N., BELSKY, J. \& DEIGHTON, J. 2013. Embedding mental health support in schools: Learning from the Targeted Mental Health in Schools (TaMHS) national evaluation. Emotional and Behavioural Difficulties, 18, 270-283.

WRIGHT, R., JOHN, L., ALAGGIA, R. \& SHEEL, J. 2006. Community-based arts program for youth in low-income communities: A multi-method evaluation. Child and Adolescent Social Work Journal, 23, 635-652.

WU, S. M. 2002. Effects of music therapy on anxiety, depression and self-esteem of undergraduates. Psychologia, 45, 104-114. 